\title{
Offshore Wind Payload Transfer Using Flexible Mobile Crane
}

\author{
M. Kjelland M. Hansen \\ Mechatronics Group, University of Agder, N-4898 Grimstad, Norway. E-mail: magnus.b.kjelland@uia.no, \\ michael.r.hansen@uia.no
}

\begin{abstract}
This article presents an offshore-simulated loading and unloading of a payload from a floating platform to a fixed structure. The experiments are performed in a dry-lab, where a Stewart platform is used to simulate the motion of the vessel. A hydraulically actuated vehicle loader crane is used to perform the tasks of payload transfer. The crane includes a hydraulic winch where the wire force is measured by a load cell. A mathematical model of the winch is derived and is experimentally verified. The control strategies include a heave compensation and a constant tension mode. A motion reference unit is used to generate the reference motion of the moving platform. Experimental results show the wire force while performing the load cases. This paper shows the advantage of using a reference motion as a feed forward control reference, instead of only relying on the constant tension.
\end{abstract}

Keywords: Heave Compensation, Constant Tension, Hydraulic Winch, Marine Operation

\section{Introduction}

As a result of all the new developments with bottom fixed and floating offshore wind turbines, the demands for operation and maintenance increase. Located 30 $\mathrm{km}$ from shore, accessibility is a challenge. In the event of a wind turbine failure, quick and reliable access is often required to get the turbine operational again. Access is also required for general inspection and maintenance of components and blades before failure. This means that maintenance or repair personnel must visit every wind turbine in a certain interval. There is a great economical potential in having a good and robust access solution for the offshore wind turbine, whether it has a fixed or floating foundation. One of the main concerns for accessing the wind turbines is the disturbance from the ocean waves. A weather window is when conditions for specific access solution to do a safe operation, is present. As production stops due to failure are costly, increasing this weather window will cause a reduction in cost and increase accessibility for offshore wind turbines.

\subsection{Offshore Access - Crane Control}

The available access solutions for offshore wind turbines include direct access with a small vessel, stabilizing gangways, and crane solutions. However, there is a great interest in finding new and better solutions.

The work presented in this paper focuses on the payload transfer between a fixed wind turbine and a floating vessel using a standard vehicle loader crane, as seen in Figure 1. Similar work regarding modeling and control of a hydraulic winch has been done by Than et al. (2002), where constant tension and heave compensation was performed in a simulated environment. Work by Neupert et al. (2008) also propose a prediction method to increase performance of heave compensation. Standard industrial crane control concerning active heave compensation and constant tension have been used for many years, especially in the oil and gas industry, see NSO (2013). An approach to damping the payload in active heave compensation has successfully been done in simulation by Yuan (2010). Work done by Johansen et al. (2003) show experimental results of an 
active heave compensation system. The paper focuses on wave synchronization when lowering a payload in a moonpool environment.

A detailed modeling of a hydraulic active heave compensated system can be found in Sverdrup-Thygeson (2007). In critical subsea operations, such as landing payloads on the seabed, there is a dependency on active heave compensation

Work with a focus on rope dynamics has been carried out by Imanishi et al. (2009) where the application is on a hydraulic winch, but without any heave compensation. Predictive control of a hydraulic winch has been done in simulation by Entao et al. (2009), where real-time parameter estimation is used to improve the motion control of the winch. Work regarding another control approach such a feed-forward control has been done by Entao and Wenlin (2009). In Haaø et al. (2012) the focus is on the friction on a heave compensation system, however the system is different from the hydraulic winch. Work regarding constant tension on a hydraulic winch is described by Engedal and Egelid (2011).

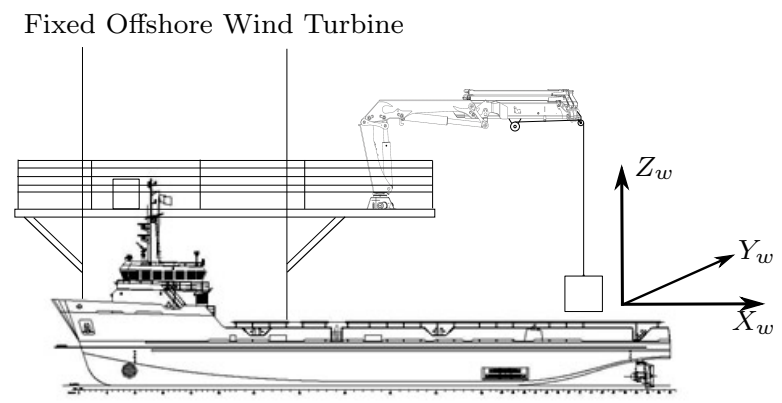

Figure 1: Marine operations - Payload transfer to/from floating vessel to fixed wind turbine

The coordinate system used in Figure 1 consists of the fixed world coordinate system:

$$
\mathbf{W}=\left[\begin{array}{c}
X_{w} \\
Y_{w} \\
Z_{w}
\end{array}\right]
$$

The $Z_{w}$ is aligned with the gravity vector but with opposite direction. This is the main input the heave compensation system requires.

\section{Considered System}

The system consists of a standard vehicle loader crane. This family of crane is regarded as light weight and having flexible structure. It also has a small footprint, but is able to handle heavy payloads in a large large workspace. The crane used is a HMF $2020 \mathrm{~K}-4$, which has a payload capacity of $1250 \mathrm{~kg}$ at 12.5 meter reach. Mounted on the crane is a hydraulically actuated winch.

\subsection{Hydraulic-Mechanical System}

The mechanical system consists of a hydraulic motor connected to a drum through a reduction gearbox. A steel wire is rolled on to the drum. The winch is mounted on a crane where the wire goes through a pulley, located at the tip of the crane. The mechanical system can be seen in Figure 2.

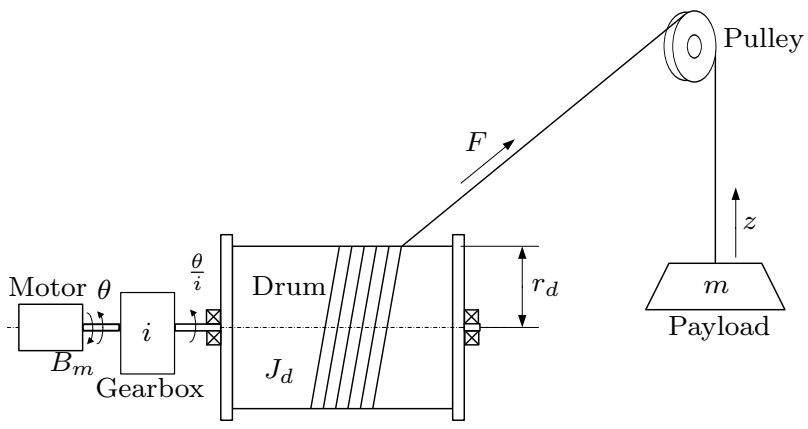

Figure 2: Mechanical system showing the motor, gearbox, drum, pulley and payload

In the figure $B_{m}$ is the motor damping, $i$ is the gear ratio of the gearbox, $\theta$ is the motor angle, $J_{d}$ and $r_{d}$ is the drum inertia and radius respectively, $m$ is the payload mass and $z$ is the vertical position of the payload.

The relation between motor angular velocity and the payload velocity is described:

$$
\dot{z}=r_{d} \cdot \frac{1}{i} \cdot \dot{\theta}
$$

The hydraulic motor is connected to an electrically actuated pressure compensated flow valve as shown in Figure 3. The load is held by two counterbalance valves and a disk brake. The brake releases when there is pressure in the lines into the motor. In the rest of the 


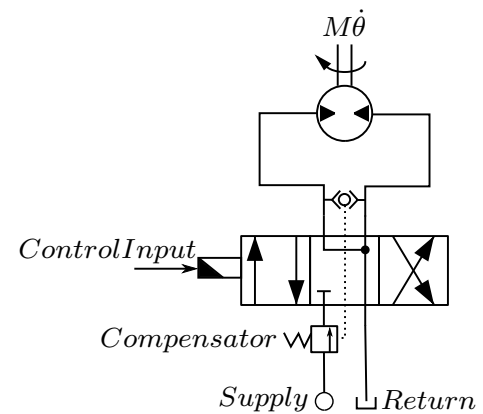

Figure 3: Hydraulic circuit showing the directional control valve and the hydraulic motor

paper, the effect of the counter balance valves and disk brake are neglected.

The opening of the valve is controlled by the voltage signal $V$. On the control spool in the valve there is a dead band that need to be excited in order for the valve to let the oil through. Otherwise the valve opening has a linear relation with the control signal as shown in Figure 4.

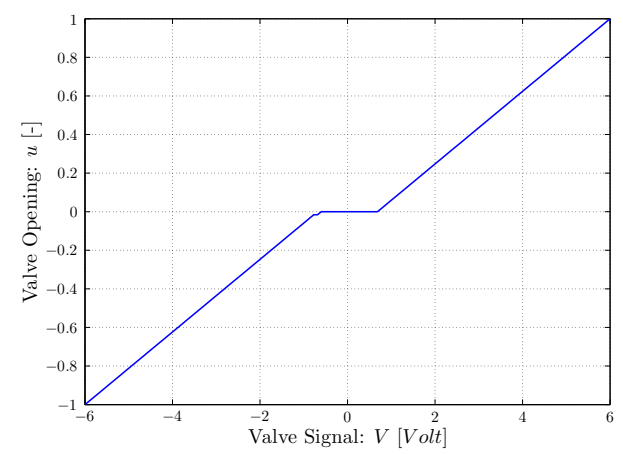

Figure 4: Valve opening vs. control signal

To account for the dead band the control voltage is based on the desired opening such as:

$$
V=\left\{\begin{array}{cc}
V_{d b}+u \cdot\left(V_{\max }-V_{d b}\right) & , \quad u>0 \\
0 & , \quad u=0 \\
-V_{d b}+u \cdot\left(V_{\max }-V_{d b}\right) & , \quad u<0
\end{array}\right\}
$$

The steady state flow equation for the valve is:

$$
Q_{v}=C_{v} \cdot u \cdot \sqrt{\Delta P}
$$

where $C_{v}$ is the valve constant, $u$ is the normalized opening of the valve and $\Delta P$ is the differential pressure over the valve edge. By using a pressure compensated valve, a small hydraulic compensator is mounted before the control edge of the valve as seen in Figure 3. This compensator keeps the $\Delta P$ in the valve constant.

\subsection{Dynamic System}

To analyse the hydro-mechanical system shown in Figure 2 and 3, the dynamic properties of the system is described mathematically. The valve dynamics is described by the first order transfer function:

$$
G_{v}(s)=\frac{Q_{v}(s)}{u(s)}=\frac{K_{v}}{\tau s+1}
$$

where $\tau$ is the time constant for the valve and $K_{v}$ is the valve gain:

$$
K_{v}=C_{v} \cdot \sqrt{\Delta P}
$$

The mass balance for the motor is:

$$
\frac{V_{f}}{4 \beta} \dot{p}_{L}=-K_{c e} p_{L}-D_{m} \dot{\theta}+Q_{L}
$$

where $V_{f}$ is the total volume of the fluids in the line, pipes and the motor, $\beta$ is the effective bulk modulus of the system, $\dot{p}_{L}$ is the pressure gradient of the load pressure, $K_{c e}$ is the leakage coefficient and $D_{m}$ is the motor displacement.

The motor moment balance is described by

$$
J_{e f f} \ddot{\theta}=-B_{m} \dot{\theta}+D_{m} p_{L}-T_{L}
$$

where $B_{m}$ is the damping coefficient for the motor and load $T_{L}$ is the load torque and $J_{\text {eff }}$ is the effective moment of inertia seen from the motor:

$$
J_{e f f}=J_{m}+\frac{J_{d}}{i^{2}}+\frac{m \cdot r_{d}^{2}}{i^{2}}
$$

where $J_{d}$ and $r_{d}$ is the drum inertia and radius respectively. $J_{m}$ is the motor inertia, $i$ is the gear ratio and $m$ is the payload mass.

As done by Than et al. (2002), the Laplace transformation of eqs. (7) and (8) results in the transfer function from the valve control signal to the velocity of the motor, assuming an infinitely fast valve

$$
\theta=\frac{\frac{K_{v}}{D_{m}} u-\frac{K_{c e}}{D_{m}^{2}}\left(1+\frac{V_{f}}{4 \beta K_{c e}} s\right) T_{L}}{\frac{s^{2}}{\omega_{h}^{2}}+\frac{2 \zeta_{h}}{\omega_{h}} s+1}
$$

where $\omega_{h}$ is the hydraulic natural frequency:

$$
\omega_{h}=\sqrt{\frac{4 \beta D_{m}^{2}}{V_{f} J_{e f f}}}
$$

and $\zeta_{h}$ is the damping ratio:

$$
\zeta_{h}=\frac{K_{c e}}{D_{m}} \sqrt{\frac{\beta J_{e f f}}{V_{f}}}+\frac{B_{m}}{4 D_{m}} \sqrt{\frac{V_{f}}{\beta J_{e f f}}}
$$


The transfer function in eq. (10) can be split up to the following two transfer functions

$$
\begin{aligned}
\frac{\Delta \theta(s)}{\Delta u(s)} & =\frac{\frac{K_{v}}{D_{m}}}{\frac{s^{2}}{\omega_{h}^{2}}+\frac{2 \zeta_{h} s}{\omega_{h}^{2}}+1} \\
\frac{\Delta \theta(s)}{\Delta T_{L}(s)} & =\frac{-\frac{K_{c e}}{D_{m}^{2}}\left(1+\frac{V_{f}}{4 \beta K_{c e}} s\right)}{\frac{s^{2}}{\omega_{h}^{2}}+\frac{2 \zeta_{h} s}{\omega_{h}^{2}}+1}
\end{aligned}
$$

Eq. (13) assumes an infinitely fast valve response. In order to include the response of the valve, the following transfer function includes the contribution from eq. (5)

$$
G_{\text {motor }}=\frac{\Delta \theta(s)}{\Delta u(s)}=\frac{\frac{\frac{K_{v}}{\tau s+1}}{D_{m}}}{\frac{s^{2}}{\omega_{h}^{2}}+\frac{2 \zeta_{h} s}{\omega_{h}^{2}}+1}
$$

Combining eqs. (2) and (15) describes the system from the valve signal to the velocity of the payload:

$$
G_{\text {system }}=\frac{\dot{z}(s)}{u(s)}=\frac{\frac{K_{v}}{\tau s+1}}{D_{m}} \frac{r_{d}}{\frac{s^{2}}{\omega_{h}^{2}}+\frac{2 \zeta_{h} s}{\omega_{h}^{2}}+1} \frac{r^{2}}{i}
$$

\section{Model Identification}

To get a model that is similar to the real system a frequency response function (FRF) obtained by an open loop feed-forward identification. A slow closed loop position feedback is implemented to keep the load from reaching any mechanical end stops.

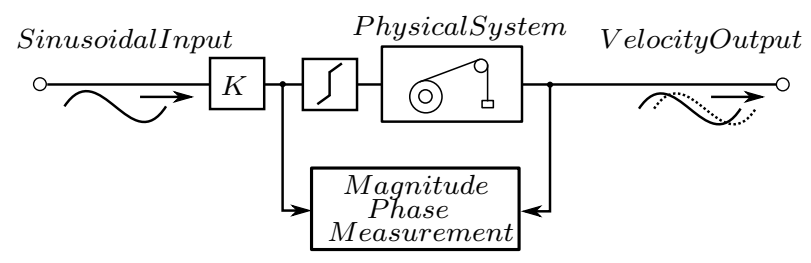

Figure 5: System for model identification

The input of the system is the valve opening signal and the output is the payload velocity, obtained by differentiating the measured position, which is based on a wire sensor connected between the crane tip and the payload. The excitation signal is a series of sinusoidal waves starting at $0.05 \mathrm{~Hz}$ and $1.4 \mathrm{~Hz}$. At each frequency the magnitude and phase shift are recorded. Figure 6 shows the measured magnitude and phase for each frequency. The FRF is estimated as a transfer function as shown in Figure 7.
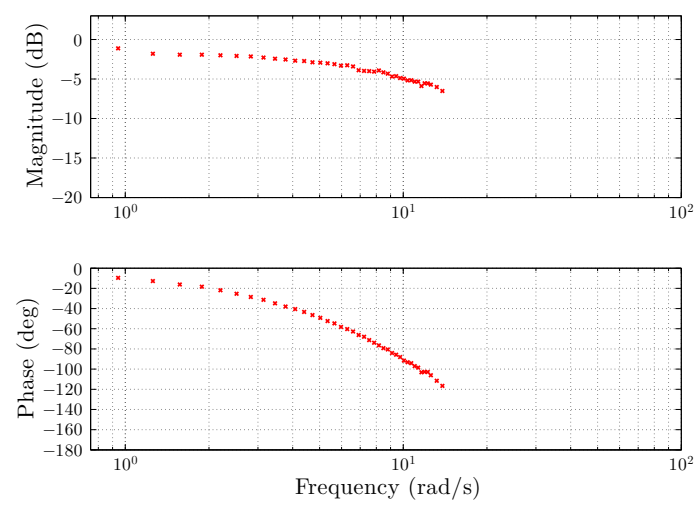

Figure 6: Measured magnitude and phase shift for each frequency
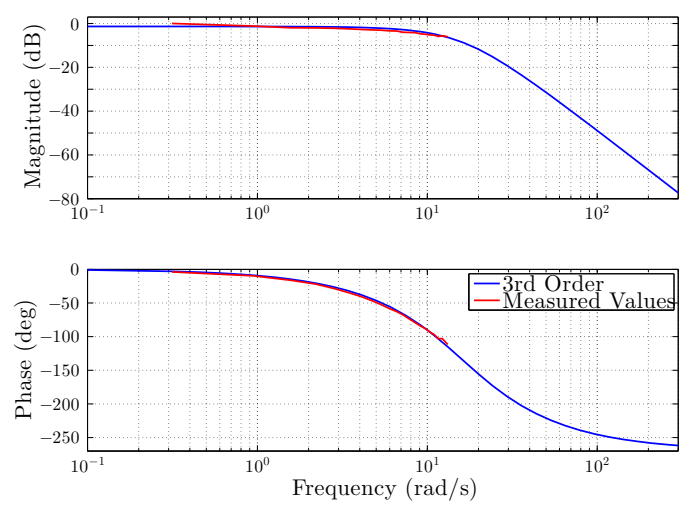

Figure 7: Estimation of transfer function for valve and system model: $G_{\text {system }}$ 
A good fit is the 3rd order transfer function:

$$
G_{\text {system }}^{\text {est }}=\frac{z_{c}}{p_{3} s^{3}+p_{2} s^{2}+p_{1} s+p_{c}}
$$

\section{Control Structure}

The control strategy chosen for the experiment was the position feedback + velocity feed forward controller.

$$
C=P_{p}\left(P_{\text {ref }}-z\right)+P_{v} V_{\text {ref }}+P_{a} A_{\text {ref }}
$$

Where $K_{p}, K_{v}$ and $K_{a}$ are proportional gains for position, velocity and acceleration respectively. The controller is used as shown in the block diagram in Figure 8.

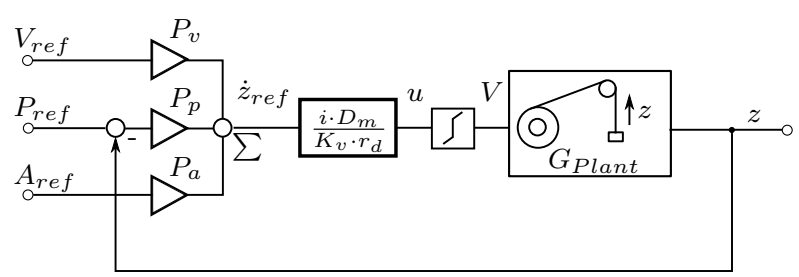

Figure 8: Control circuit strategy

There is a dead-band compensator to avoid the deadband in the spool of the hydraulic valve, given by eq.(3). $P_{r e f}, V_{\text {ref }}$ and $A_{\text {ref }}$ are the reference position, velocity and acceleration that are measured by a sensor.

The Bode plot in Figure 9 shows the open loop response and the closed loop using the proposed controller shown in Figure 8.
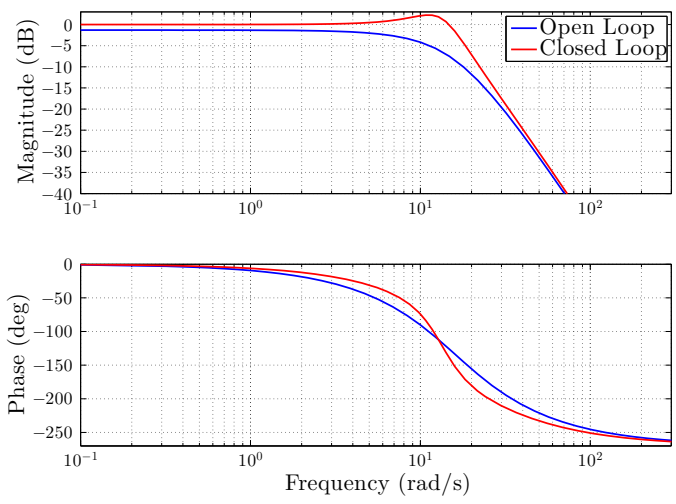

Figure 9: Closed loop Bode plot

The closed loop system gives a good tracking over the frequencies. Normal wave periods can be from 4 to 16 $\mathrm{s}$. At $4 \mathrm{~s}$ the closed loop Bode plot shows a magnitude of $0.0896 \mathrm{~dB}$ and the phase lag is $-9.94^{\circ}$.

\subsection{Heave Compensation}

To perform heave compensation, a motion sensor is used which enables measurement of the acceleration, velocity and position of the moving target. The goal for the winch system is to track this motion. The controller shown in Figure 8 is used for this purpose.

\subsection{Constant Tension}

By turning the position of the hydraulic motor, the wire is stretched. Based on the flexibility of the crane, it is possible to control the winch tension, thus the tension in the load. A closed feedback loop $\mathrm{P}$ controller is used to control the velocity of the motor as shown in Figure 10.

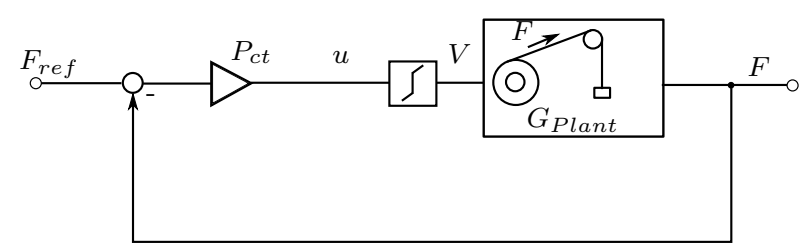

Figure 10: Control circuit for constant tension

\subsection{Combined Control Strategy}

Being able to control both the tension in the wire and compensating for the heave, these control strategies can be combined to perform the following tasks.

\subsubsection{Landing}

The goal is that the motion of the load is phased in with the wave motion, while slowly lowering the payload. This will continue as long as there is no tension in the wire.

\subsubsection{Lifting}

For this case the system starts with constant tension combined with the velocity feed forward. The system switches to hoist at the time when the target has a positive wave amplitude and a positive velocity. The hoist mode is a constant velocity command for the hydraulic motor.

\subsection{Modes}

The whole control system can be divided into three main modes. Each mode can control 5 states. The three modes are Active Heave Compensation (AHC), constant Tension (CT) and hoisting. The modes and 
Table 1: Modes of Operation

\begin{tabular}{cccc}
\hline \hline & AHC & CT & Hoist \\
\hline 1: Position & $\mathrm{x}$ & - & - \\
2: Velocity & $\mathrm{x}$ & $\mathrm{x}$ & - \\
3: Acceleration & $\mathrm{x}$ & $\mathrm{x}$ & - \\
4: Load Compensation & - & $\mathrm{x}$ & - \\
5: Constant Hoist & - & - & $\mathrm{x}$ \\
\hline
\end{tabular}

states are shown in Table 1.

To switch between modes, either a criterion must be fulfilled or a button is pressed (typical operator).

Each of the five states is included in the control system strategy. They can either be true or false which will pass or stop the signal going through. Combining the control circuits shown in Figure 8 and 10 with the state control, a new control circuit is is developed shown in Figure 11.

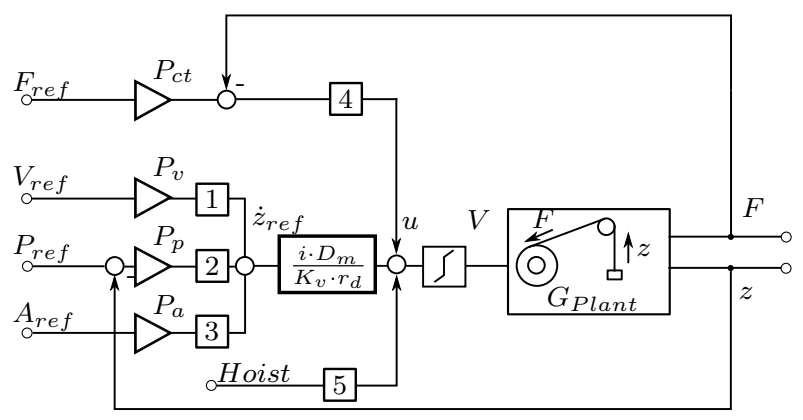

Figure 11: Mode based control circuit

The rules for switching are defined as follows:

The system always starts in AHC. To switch from AHC to $\mathrm{CT}$ the payload measurement must be under the tension threshold for $0.5 \mathrm{~s}$. After this switch, the system cannot return to $\mathrm{AHC}$. The $\mathrm{CT}$ mode is switched to Hoist by the operator and when the wave motion is below a velocity amplitude threshold.

\section{Experimental Results}

\subsection{Tracking of Motion Reference}

Tracking of the reference signals is shown in Figure 14. The rest of the results show a sequence of:

1. Synchronising the motion of the load with the target.

2. Landing the payload.

3. Switching to CT mode.

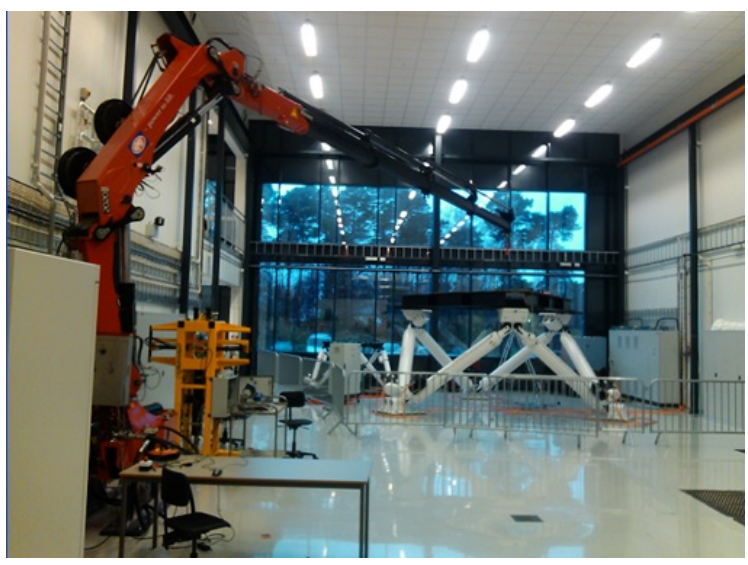

Figure 12: Experimental setup showing the loader crane and the Stewart platform used to simulate a floating vessel

4. Lifting the payload while in CT mode.

\subsubsection{Active Heave Compensation}

Shown in Figure 13, starting at a fixed position, the winch starts to synchronise with the motion of the referenced target at $t=22 \mathrm{~s}$.

\subsubsection{Landing}

Figure 15 shows the landing of the payload. While actively heave compensating the payload, the landing procedure starts at $t=43.5 \mathrm{~s}$ and has reached the desired wire force at $t=47.5 \mathrm{~s}$. The wire force is slowly
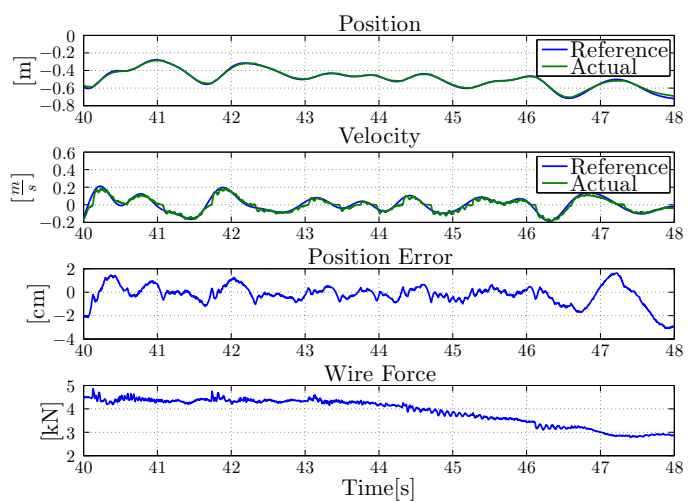

Figure 15: Landing the payload

decreasing as the load is lowered.

\subsubsection{Constant Tension}

When the wire tension has reached the desired force, shown in Figure 16, the constant tension mode is 

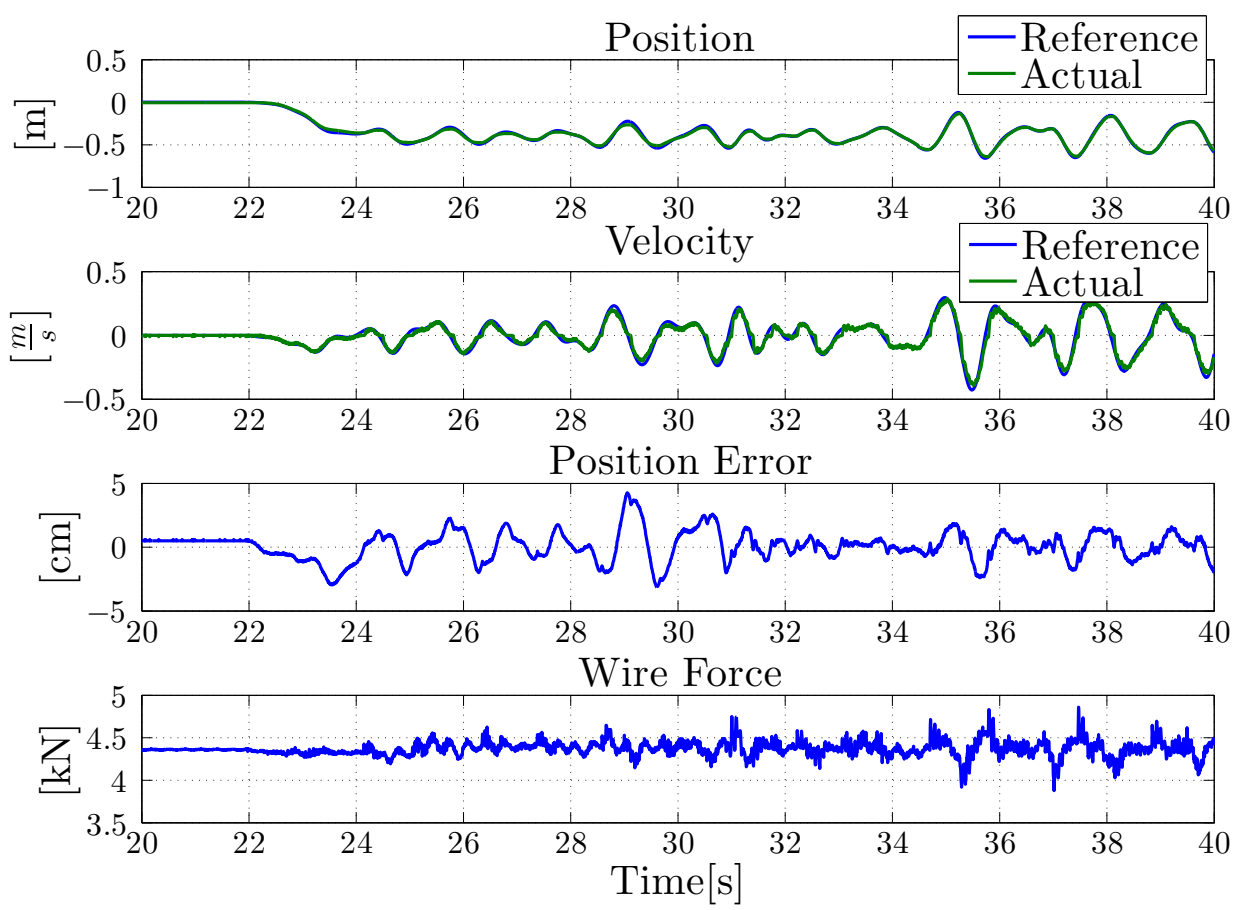

Figure 13: Synchronising motion with the moving target

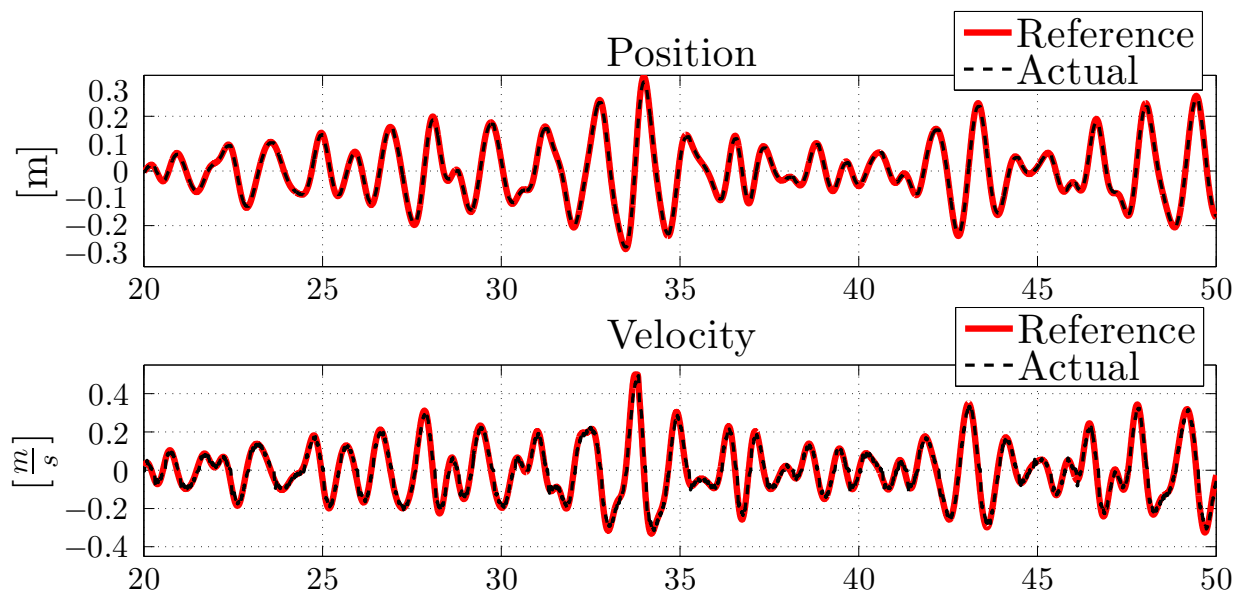

Position Error

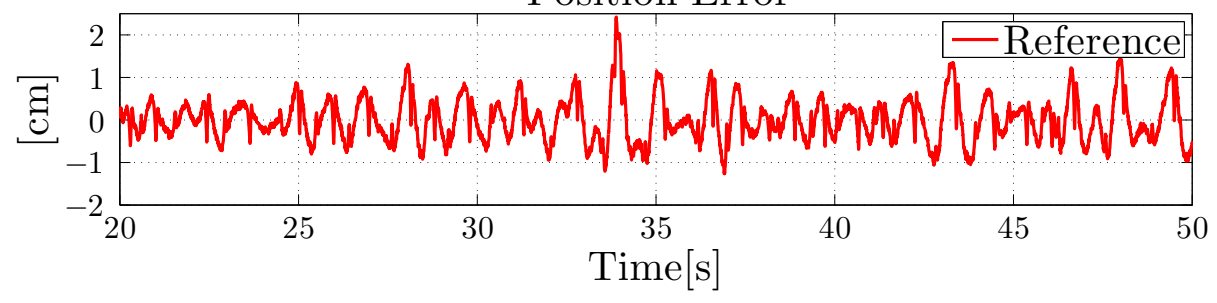

Figure 14: Active heave compensation: The winch is controlled to follow a moving target 
switched on. The winch velocity is controlled to keep the wire tension constant. It is important to not lift the payload in this mode, as an impact would occur when the payload hits the target.
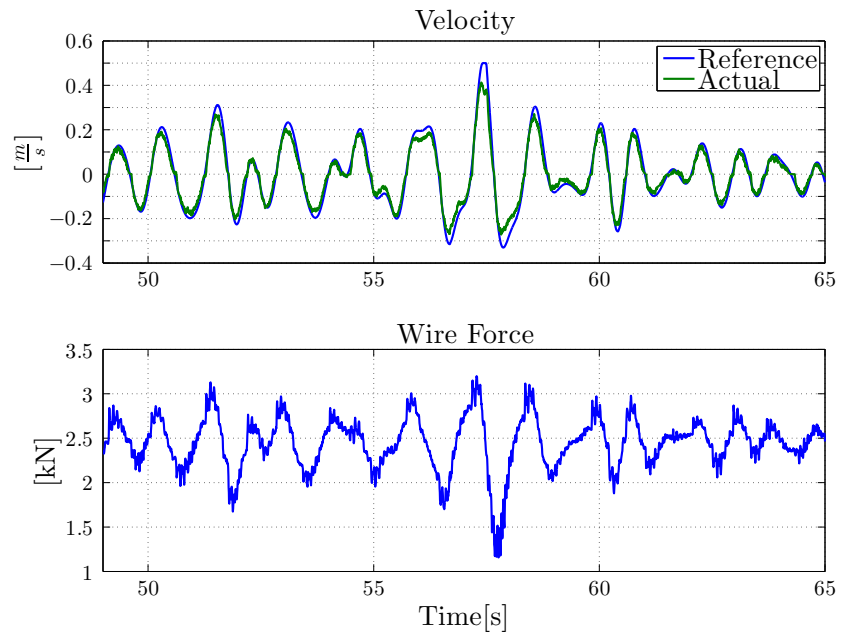

Figure 16: Constant tension

\subsubsection{Lifting}

When the constant tension mode is active, the payload can be lifted from the moving target. In Figure 17 at $t=65.3 s$, when the target's positive velocity is high, the lifting procedure is activated. The winch then lifts the payload at a constant velocity.
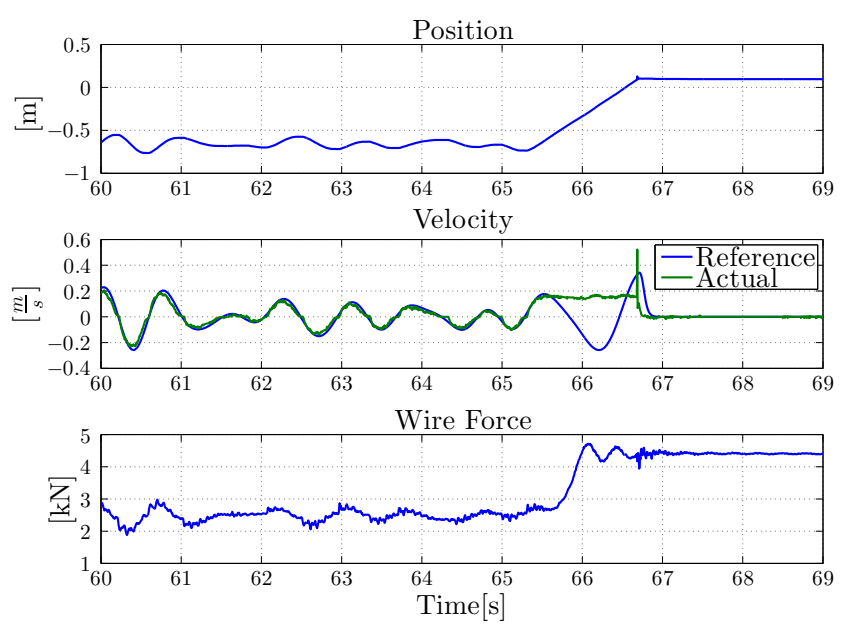

Figure 17: Lifting the payload

\section{Conclusion}

Demonstrated in this paper is the use of a heave compensated hydraulic winch. The model of the hydro-mechanical winch system is derived and is experimentally verified. The control strategy proposed shows that the motion of the payload is tracking the reference target. The constant tension control reduces the fluctuations of the wire forces. Using the system with the proposed control scheme shows a successful landing and lifting of a $400 \mathrm{~kg}$ payload on a constantly moving target. This was done experimentally by the use of a full scale hydraulic loader crane which includes a hydraulic winch. To achieve motion of the reference target, a Stewart platform was used, programmed to move according to an ocean wave spectrum.

Table 2 shows some of the parameters used in this paper.

Table 2: Parameters

\begin{tabular}{cccc} 
Parameters & Sym. & SI-Units & $\begin{array}{c}\text { Hydraulic- } \\
\text { Units }\end{array}$ \\
\hline Valve Gain & $K_{v}$ & $1.1 e^{-3}\left[\frac{\mathrm{m}^{3}}{\mathrm{~s}}\right]$ & $65\left[\frac{\mathrm{l}}{\mathrm{min}}\right]$ \\
Spool Diff. & $\Delta P$ & $7 e^{5}[\mathrm{~Pa}]$ & $7[\mathrm{bar}]$ \\
Pressure & & & \\
Motor & $D_{m}$ & $2 e^{-4}\left[\mathrm{~m}^{3}\right]$ & $200\left[\mathrm{~cm}^{3}\right]$ \\
Displacement & $\mathrm{i}$ & $1: 5.04$ & \\
Gear Ratio & $r_{d}$ & $0.15[\mathrm{~m}]$ & \\
Drum Radius & $m$ & $400[\mathrm{~kg}]$ & \\
Payload Mass & & & \\
& $P_{p}$ & 10 & \\
Position Gain & $P_{v}$ & 1 & \\
Velocity Gain & $P_{a}$ & 0.1 & \\
Acceleration Gain & $P_{c t}$ & 0.24 & \\
CT Gain & & & \\
Zero Constant & $z_{c}$ & 0.8594 & \\
Third Pole & $p_{3}$ & 0.0002344 & \\
Second Pole & $p_{2}$ & 0.01006 & \\
First Pole & $p_{1}$ & 0.1625 & \\
Pole Constant & $p_{c}$ & 1 & \\
\hline
\end{tabular}




\section{Acknowledgments}

This work has been funded by NORCOWE under grant 193821/S60 from the Research Council of Norway. NORCOWE is a consortium with partners from industry and science, hosted by Christian Michelsen Research.

\section{References}

NSLT - The $18^{\text {th }}$ North Sea Offshore Crane and Lifting Conference, Stavanger, Norway - Norwegian Society of Lifting Technology, 2013.

Engedal, H. and Egelid, P. M. Modeling, simulation, and testing of constant tension system on winch. MSc diploma thesis, University of Agder, 2011.

Entao, Z. and Wenlin, Y. Research on the motion tracking feedforward control of hydraulic winch. In Computer Engineering and Application, 2009 International Conference on. 2009.

Entao, Z., Wenlin, Y., and Junzhe, L. Predictive control of hydraulic winch motion control. In Computer Science and Information Technology, 2009. ICCSIT 2009. $2^{\text {nd }}$ IEEE International Conference on. pages 1-4, 2009. doi:10.1109/ICCSIT.2009.5234639.

Haaø, J., Vangen, S., Tyapin, I., Choux, M., Hovland, G., and Hansen, M. R. The effect of friction in passive and active heave compensation of crown block mounted compensators. In 2012 IFAC Workshop on
Automatic Control in Offshore Oil and Gas Production. 2012. doi:10.3182/20120531-2-NO-4020.00040.

Imanishi, E., Nanjo, T., and Kobayashi, T. Dynamic simulation of wire rope with contact. Journal of $\mathrm{Me}$ chanical Science and Technology, 2009. 23(4):10831088. doi:10.1007/s12206-009-0345-0.

Johansen, T., Fossen, T., Sagatun, S. I., and Nielsen, F. Wave synchronizing crane control during water entry in offshore moonpool operations - experimental results. Oceanic Engineering, IEEE Journal of, 2003. 28(4):720-728. doi:10.1109/JOE.2003.819155.

Neupert, J., Mahl, T., Haessig, B., Sawodny, O., and Schneider, K. A heave compensation approach for offshore cranes. In American Control Conference, 2008. pages 538-543, 2008. doi:10.1109/ACC.2008.4586547.

Sverdrup-Thygeson, J. Modeling and Simulation of an Active Hydraulic Heave Compensation System for Offshore Cranes. diploma thesis, Norwegian University of Science and Technology, 2007.

Than, T. K., Langen, I., and Birkeland, O. Modelling and simulation of offshore crane operations on a floating production vessel. 2002.

Yuan, Q. Actively damped heave compensation (adhc) system. In American Control Conference (ACC), 2010. pages 1544-1549, 2010. doi:10.1109/ACC.2010.5531545. 